
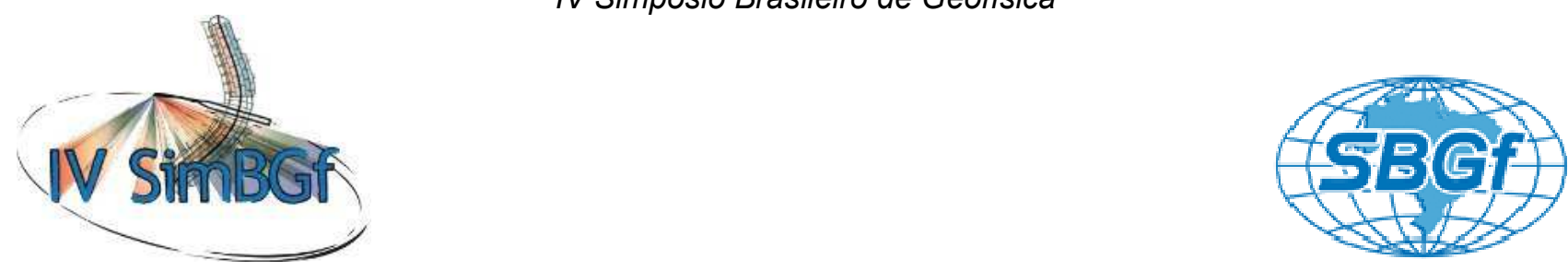

\title{
Testes para seleção de parâmetros de aquisição do método MASW realizados em um estudo em Ubatuba/SP
}

\author{
Sérgio Bezerra Lima Júnior, Renato Luiz Prado; Universidade de São Paulo. Instituto de Astronomia, Geofísica e Ciências \\ Atmosféricas.
}

Copyright 2008, SBGf - Sociedade Brasileira de Geofísica

Este texto foi preparado para a apresentação no IV Simpósio Brasileiro de Geofísica, Belém, 14 a 17 de novembro de 2010. Seu conteúdo foi revisado pelo Comitê Técnico do IV SimBGf, mas não necessariamente representa a opinião da SBGf ou de seus associados. É proibida a reprodução total ou parcial deste material para propósitos comerciais sem prévia autorização da SBGf

\section{Resumo}

Este trabalho discute o emprego do método MASW (multichannel analysis of surface waves) a partir de resultados obtidos em um levantamento em área de erosão e escorregamento no município de Ubatuba, estado de São Paulo. Buscou-se obter o perfil 1D do campo de velocidades da onda $S$ (Vs) a partir da inversão da curva de dispersão obtida do registro das ondas superficiais. Aqui são discutidos aspectos relacionados aos parâmetros de aquisição, sendo testados vários offsets mínimos e geofones de freqüências naturais distintas, visando uma melhor qualidade dos dados. O resultado apresentou coerência com os obtidos de outras investigações geofísicas (GPR) feitas no local, atestando a sua eficiência. Para os sedimentos mais superficiais foram mapeadas três interfaces: a primeira a um metro de profundidade, a segunda a quatro metros e a terceira a oito metros.

\section{Introdução}

Este trabalho apresenta resultados de ensaios MASW multichannel analysis of surface waves (Park et al., 1999; Xia et al., 1999) realizados na região do município de Ubatuba, local de ocorrência de numerosos movimentos de massa no Estado de São Paulo (Fapesp, 2006).

Os ensaios tiveram como objetivos: i) avaliar alguns aspectos do arranjo de campo e tipos de sensores e suas relações com a qualidade do dado; ii) a obtenção de perfis de velocidade de onda $S$ visando à caracterização geotécnica dos solos não saturados.

Os dados foram obtidos com um arranjo multicanal, assim como é feita a aquisição na sísmica de reflexão convencional.

O método MASW fundamenta-se no caráter dispersivo da onda Rayleigh em meios estratificados. Dos sismogramas se obtém a curva de dispersão, que apresenta a relação funcional entre a velocidade de fase e a freqüência da onda Rayleigh e cujo comportamento, em última análise, dependerá das características do semi-espaço geológico. A partir da inversão da curva de dispersão pode-se inferir a distribuição vertical das velocidades da onda $\mathrm{S}$.

\section{Metodologia}

Deve-se buscar nesses ensaios, tanto quanto possível, o registro das ondas Rayleigh em uma ampla faixa de freqüências e minimizar a interferência de outros eventos, tais como os da refração das ondas de corpo. Com esses objetivos foram testados diferentes geofones e espaçamentos mínimos entre fonte e arranjo.

Para a geração da energia sísmica foi utilizado o impacto de um martelo de aproximadamente oito quilogramas sobre uma placa metálica de aproximadamente 25 centímetros de diâmetro.

O equipamento empregado foi o sismógrafo Geode da Geometrics Inc.. Nos ensaios foram utilizados simultaneamente três grupos de 24 geofones de freqüências naturais de $4,5 \mathrm{~Hz}, 14 \mathrm{~Hz}$ e $28 \mathrm{~Hz}$.

Cada grupo de geofones constituiu um arranjo linear e os três arranjos foram posicionados paralelamente entre si a uma distância de um metro. O espaçamento entre os geofones ao longo do arranjo também foi de um metro (Figura 1).

Foram também testados diferentes afastamentos mínimos (offset) para a geração da onda, desde um metro até quinze metros.

A definição do melhor afastamento mínimo e extensão de arranjo estão relacionadas aos chamados efeitos de "campo próximo" e "campo distante". O efeito de "campo próximo" diz respeito à distância mínima necessária para que a onda Rayleigh se comporte na sua trajetória como uma frente de onda plana horizontal. Esta foi, portanto, a motivação para se testar diversos offsets mínimos.

Por outro lado, se o offset máximo for muito grande, os componentes de alta freqüência da energia das ondas superficiais não serão dominantes nos componentes de freqüência do espectro, prevalecendo 0 conteúdo associado às ondas de corpo.

Assim, depois de uma avaliação preliminar do conteúdo espectral dos dados adquiridos com os diferentes offsets, alguns registros foram decompostos na forma de registros de varredura de freqüência (swept-frequency record), como sugerido por Park et al. (1999). Nessa 
transformação faz-se a convolução do traço sísmico, $r(t)$, com uma função de estiramento, $\mathrm{s}(\mathrm{t})$ (Coruh, 1985).

$$
r_{s}(t)=r(t)^{*} s(t)
$$

onde * denota a operação de convolução.

A função de estiramento é uma função senoidal com variação da freqüência em função do tempo, da forma:

$$
s(t)=\operatorname{sen}\left(2 \pi f_{1} t+\frac{\pi\left(f_{2}-f_{1}\right) t^{2}}{T}\right)
$$

onde $f_{1}, f_{2}$ são a menor e maior freqüências do espectro, e T o comprimento de $\mathrm{s}(\mathrm{t})$.

\section{Resultados}

A Figura 2 apresenta os dados transformados, adquiridos com offsets mínimos de um metro, quatro e dez metros com geofones de $4,5 \mathrm{~Hz}$.

Nota-se que os dados com offset mínimo de quatro metros sofrem influência somente nos maiores offsets, mas mesmo assim a partir das freqüências mais elevadas. Já os dados com offset de um metro trazem o efeito de campo próximo e os de offset de dez metros um efeito de campo remoto mais significativo no espectro de freqüência de interesse.

Em relação aos diferentes geofones empregados, observou-se que para freqüências maiores, ou seja, menores comprimentos de onda, os geofones de maiores freqüências naturais apresentam uma melhor resposta na curva de dispersão.

Para os dados obtidos com os geofones de freqüência natural de 28 Hertz, a curva de dispersão se estende até uma freqüência próxima de 50 Hertz (Figura 3 (c)) e para os obtidos com os geofones de freqüência natural 4,5 Hertz (Figura 3 (a)) o espectro se desloca para uma faixa de menores freqüências, ou seja, maiores comprimentos de onda (maiores profundidades). Os dados obtidos com os geofones de freqüência natural de $14 \mathrm{~Hz}$ (Figura 3 (b)) apresentam uma resposta intermediária.

A análise comparativa entre os resultados das curvas de dispersão obtidas com os diferentes geofones indicou que os geofones de freqüência natural de $4,5 \mathrm{~Hz}$ permitiam uma banda de espectro mais ampla, envolvendo principalmente as freqüências mais baixas, trazendo teoricamente menor ambigüidade na identificação do modo fundamental das ondas Rayleigh.

A seguir analisou-se o efeito do arranjo de campo na obtenção da curva de dispersão. Foram obtidas as curvas de dispersão dos sismogramas adquiridos com offsets mínimos de um, quatro e dez metros (geofone de $4,5 \mathrm{~Hz}$ ). A melhor relação sinal/ruído foi obtida utilizando afastamentos mínimos pequenos, um e quatro metros (Figura 4).

A curva de dispersão final resultou do empilhamento de três diferentes curvas geradas de sismogramas adquiridos com offsets mínimos de quatro, cinco e seis metros.

O resultado da inversão é apresentado na Figura 5. Foram mapeadas três interfaces, a um, quatro e oito metros de profundidade. Levantamento executado na mesma área com o método GPR ratificou a existências das duas interfaces mais rasas. Esses estratos foram associados a um solo residual composto por argila pouco arenosa, amarela, com grânulos de quartzo intercalados e com a presença de material orgânico intercalado $(0$ $0,8 \mathrm{~m}$ ); o segundo composto por material argiloso pouco arenoso, minerais micáceos, com pequenos grãos de quartzo dispersos, sem estrutura da rocha mãe $(0,8-5$ $\mathrm{m})$; o terceiro de material areno-argiloso a argilo-arenoso, de cor variegada e com a presença de estrutura reliquiar $(5-12 \mathrm{~m})$. A Figura 6 apresenta a distribuição granulométrica obtida de amostras de trado coletadas no mesmo local dos ensaios geofísicos.

\section{Conclusões}

A análise comparativa entre os resultados das curvas de dispersão obtidas com os diferentes geofones, indicou que os de freqüência natural de $4,5 \mathrm{~Hz}$ permitiam uma banda de espectro mais ampla, envolvendo principalmente as freqüências mais baixas, embora a área de estudo não tenha propiciado a geração de ondas de baixa freqüência devido à remoção do horizonte mais superficial do solo.

A análise dos registros transformados para o domínio de varredura de freqüência é de grande auxilio para a escolha do offset mínimo a ser adotado, pois auxilia na identificação dos efeitos de campo próximo e remoto.

O empilhamento das curvas de dispersão obtidas dentro de uma faixa ótima de offsets mínimos aumenta a relação $S / R$ e contribui para o resultado final da inversão. Neste caso, a curva de dispersão final resultou do empilhamento das curvas geradas a partir de registros adquiridos com offsets mínimos de quatro, cinco e seis metros. Com a inversão foi possível mapear três interfaces a um, quatro e oito metros de profundidade, correlacionadas às mudanças de composição granulométrica verificadas por amostragem direta na mesma área do ensaio geofísico, evidenciando a eficiência do método MASW.

\section{Referências}

Coruh, C., 1985. Stretched automatic amplitude adjustment of seismic data: Geophysics, 50, 252-256.

Fapesp, 2006. Diretrizes para regeneração sócioambiental de áreas degradas por mineração de saibro (caixas de empréstimo), Ubatuba, SP. $2^{\circ}$ Relatório Programa de pesquisas em políticas públicas - processo Fapesp $n^{\circ}$ 03/07182-5).

Park, C.B.; Miller, R.D.; Xia, J., 1999. Multichannel analysis of surface waves. Geophysics, v.64, n.3, p.800808. 
Xia, J.; Miller, R.D.; Park, C.B., 1999. Estimation of nearsurface shear-wave velocity by inversion of Rayleigh waves. Geophysics, v.64, n.3. p.691-700.

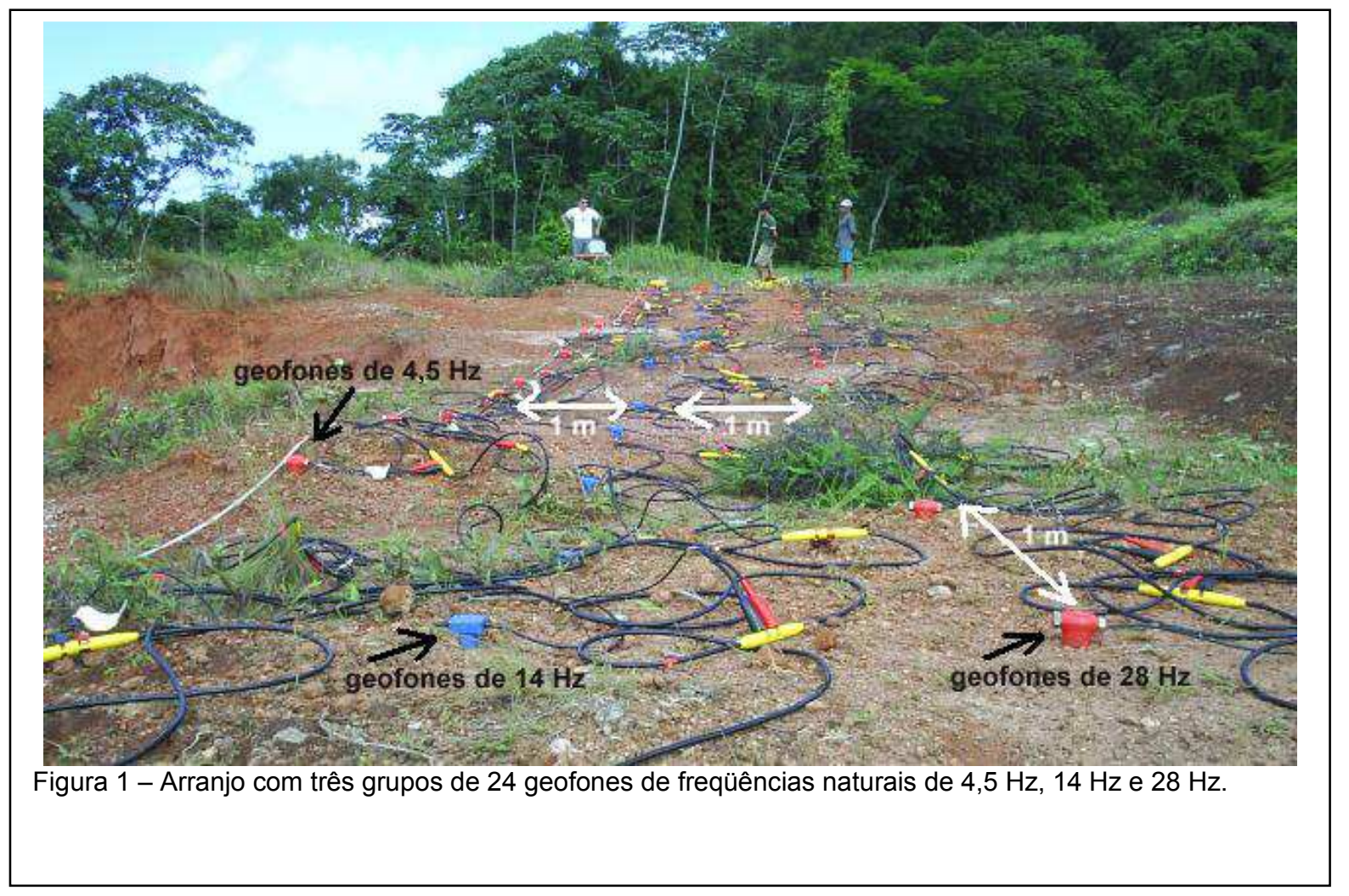




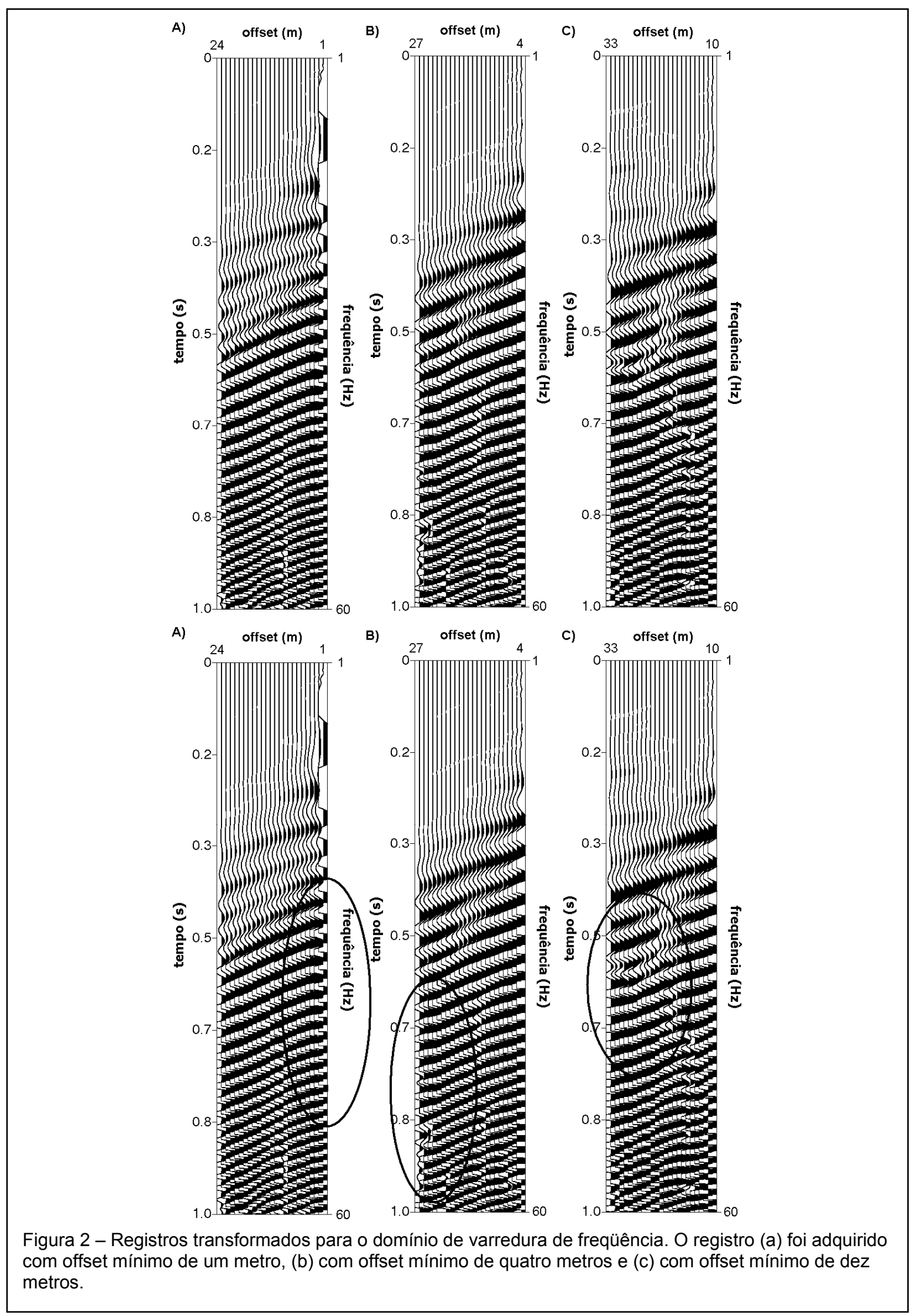

IV Simpósio Brasileiro da SBGf - Brasília 2010 

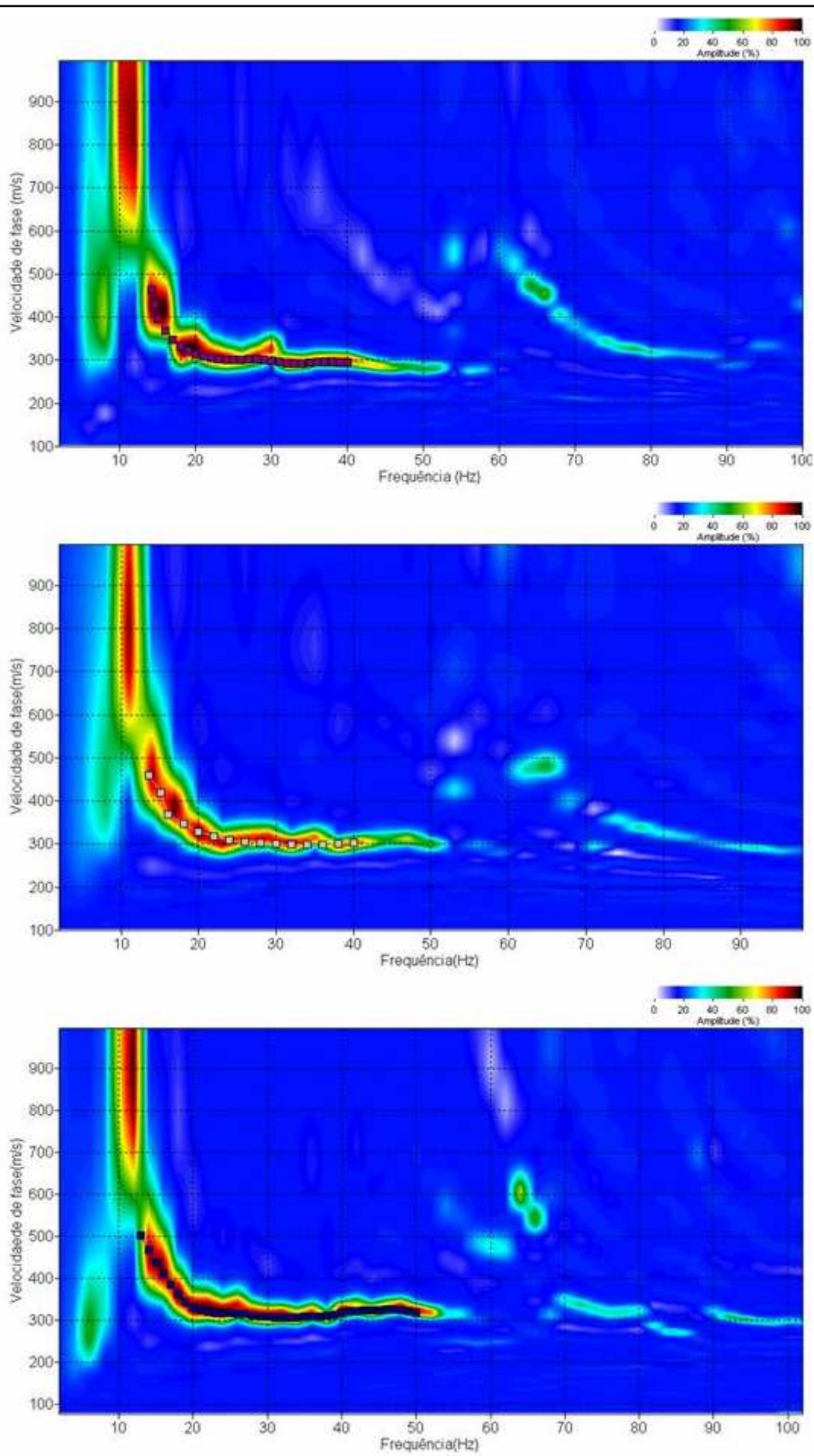

Figura 3 - Curvas de dispersão para os dados de afastamento mínimo de três metros dos dados adquiridos com geofones de 4,5 Hertz, 14 Hertz e 28 Hertz. 

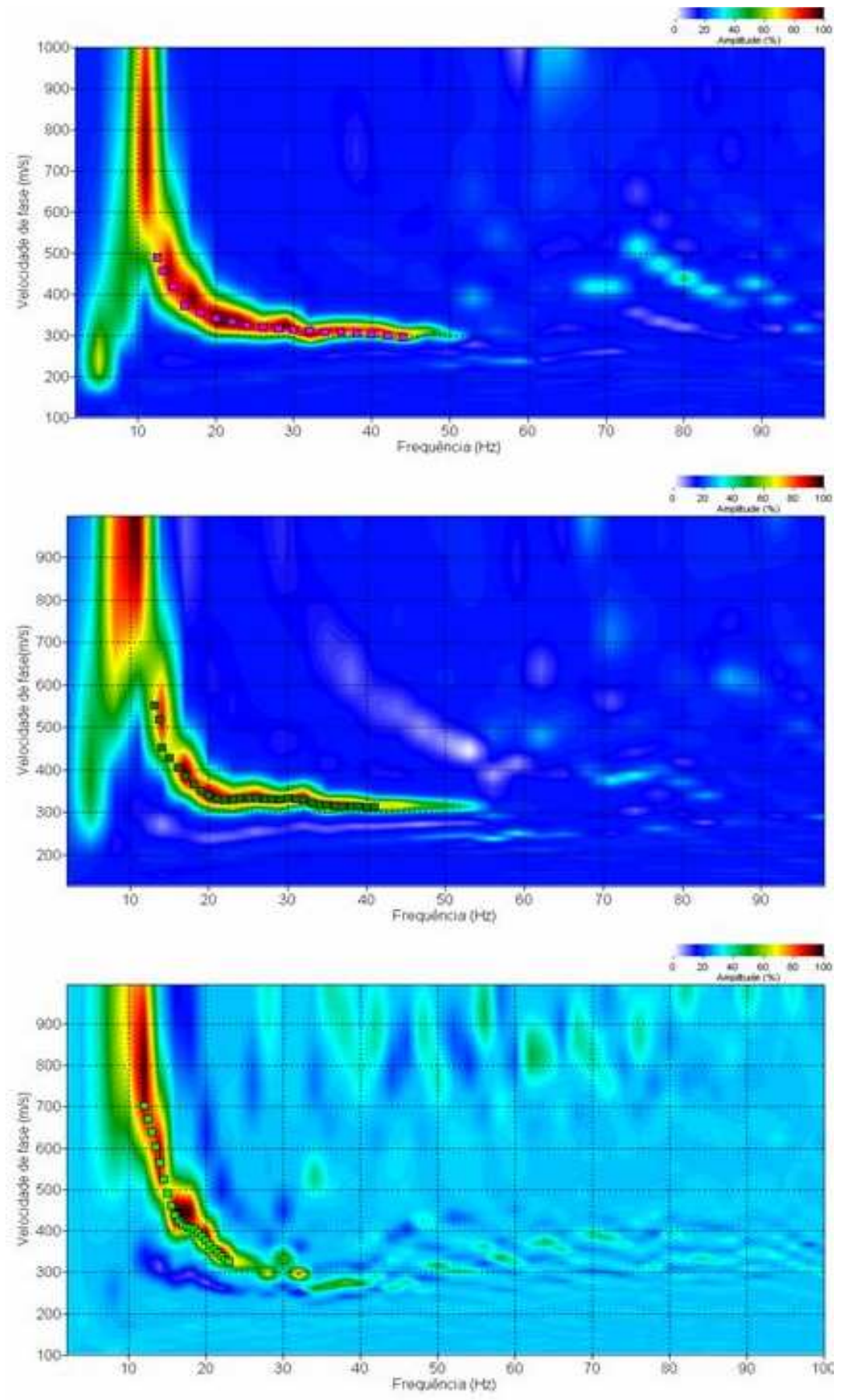

Figura 4 - Curvas de dispersão dos dados obtidos com offset mínimo de um, quatro e dez metros. 


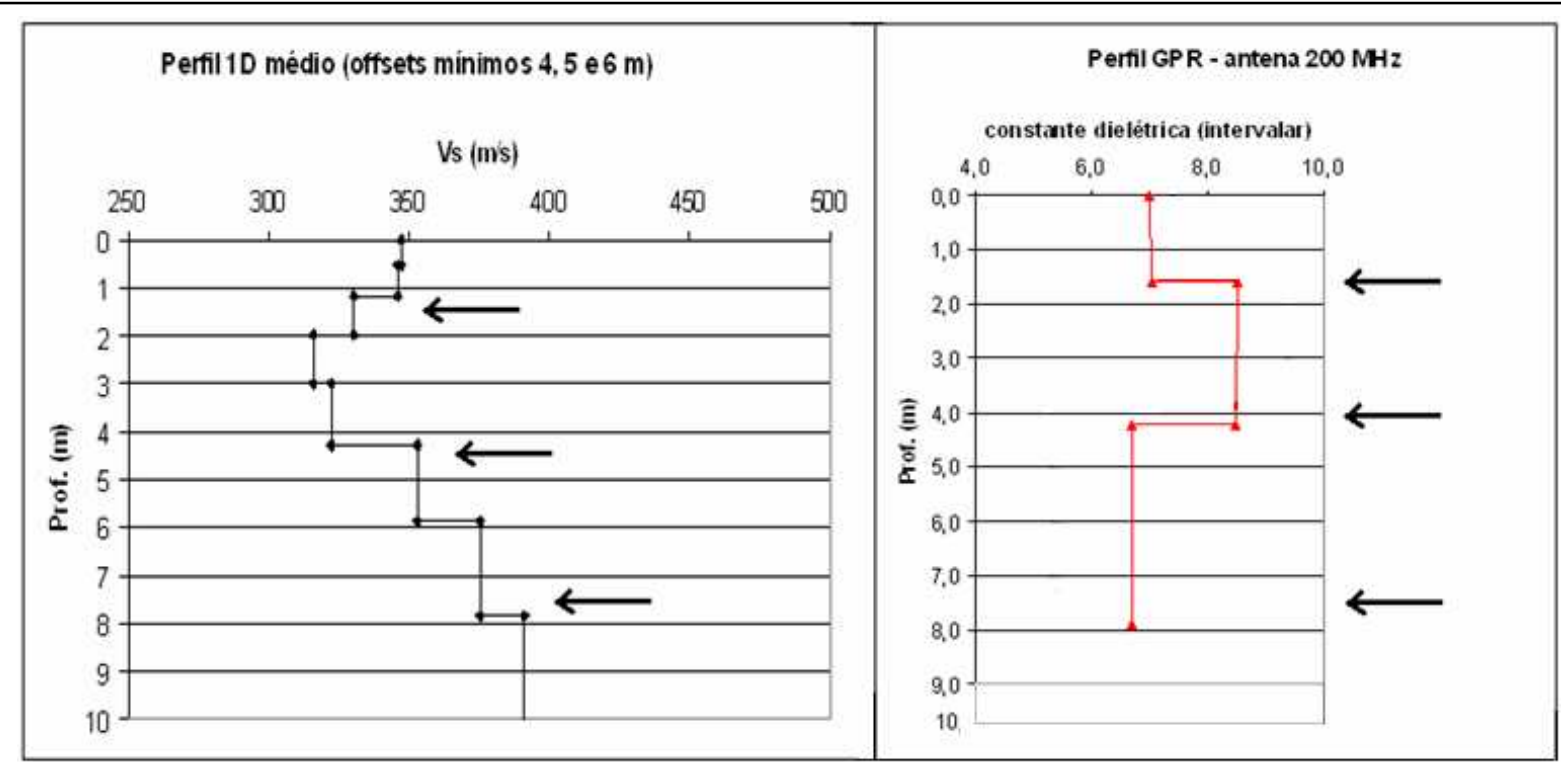

Figura 5 - Perfil 1D de inversão e de GRP respectivamente.

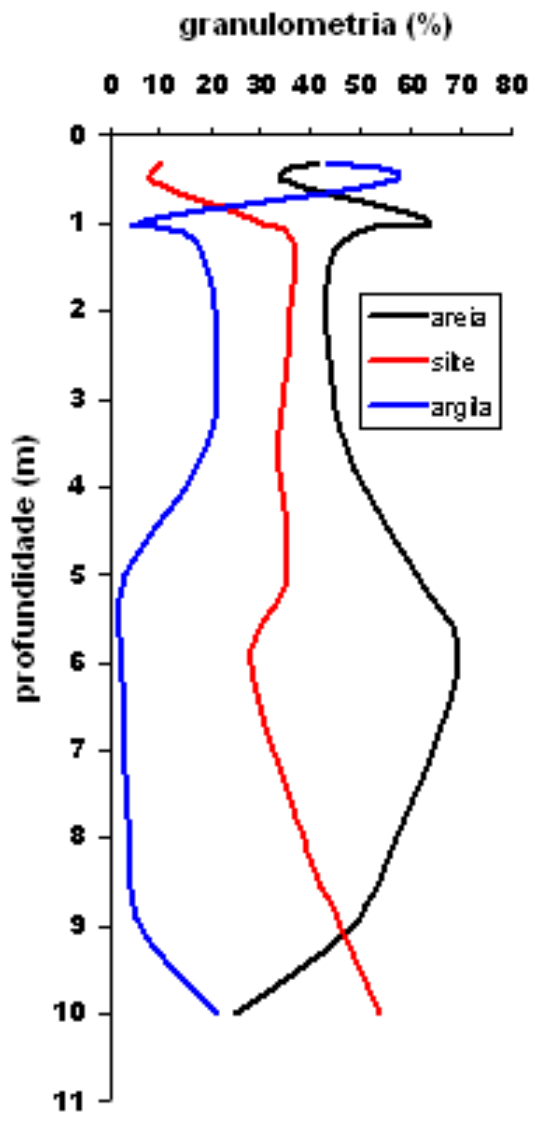

Figura 6 - Curvas das variações granulométricas das amostras coletadas no local dos ensaios geofísicos 